OPEN ACCESS

Edited by:

Wei Wang,

Hohai University, China

Reviewed by:

Liguo Jin,

China Earthquake Administration,

China

Long Wang,

Jiangnan University, China

${ }^{*}$ Correspondence:

Jun Yu

yujunhis/@foxmail.com

Specialty section:

This article was submitted to Interdisciplinary Physics,

a section of the journal

Frontiers in Physics

Received: 17 September 2021

Accepted: 15 October 2021

Published: 15 November 2021

Citation:

Cao X, Zhang H, Yu J, Yu T and Qing Y

(2021) Experiment on Strength and

Failure Behavior of Sandstone

Containing Pre-Existing Cracks Under

Brazilian Compression.

Front. Phys. 9:778662.

doi: 10.3389/fphy.2021.778662

\section{Experiment on Strength and Failure Behavior of Sandstone Containing Pre-Existing Cracks Under Brazilian Compression}

\author{
Xiaojian Cao, Han Zhang, Jun Yu*, Tianchong Yu and Yuxing Qing \\ School of Transportation and Civil Engineering, Nantong University, Nantong, China
}

Determination of the mechanical properties of rock containing pre-existing cracks under tension condition is of great significance to understand the failure process of rock in engineering. This paper presents the experimental results of sandstone containing preexisting cracks under Brazilian compression. The characteristics of the microcracks were analyzed by a scanning electron microscope. The results show that the rock containing pre-existing cracks has an obvious anisotropic characteristic. When the crack inclination is $45^{\circ}$, the rock has the minimum tensile strength and the weakest axial deformation resistance.

Keywords: mechanical properties, Brazilian test, pre-existing crack, strength, failure behavior

\section{INTRODUCTION}

Crack is widely distributed in the rock mass, which is an important reason for significant anisotropy in the mechanical properties of rock. Many engineering activities and geological disasters had close connection with the new crack emanating from the pre-existing crack as well, including hydraulic fracture [1], the failure of surrounding rock [2], and the rock-slope collapse [3]. Therefore, to maintain the safety and stability of the engineering project and environment, it is practically important to study the effect of cracks on the mechanical properties of rock.

Considerable efforts have been done to study the strength and failure behavior of rock materials containing cracks through laboratory tests and numerical simulations [4-8]. The fracture mode and initiation mechanism of crack under compression condition are also well analyzed. However, the mechanical behavior of cracks under tensile condition is still a great challenge to safety of rock engineering. Thus, the study of strength and failure behavior of sandstone containing pre-existing cracks under Brazilian compression was carried out.

\section{EXPERIMENTAL METHOD AND MATERIALS}

The sandstone used in this study was drilled from a hydropower station in Southwest China. The mean natural density is $2.18 \mathrm{~g} / \mathrm{cm}^{3}$. The sandstone has a homogenous structure; therefore, the specimens without pre-existing cracks are assumed to be not anisotropic obviously at sample scale. The sandstones were cut and polished to disk-shaped specimens of $50 \mathrm{~mm}$ diameter and $25 \mathrm{~mm}$ thickness; then, the cross-cutting cracks through the center of disks were drilled in the specimens, 


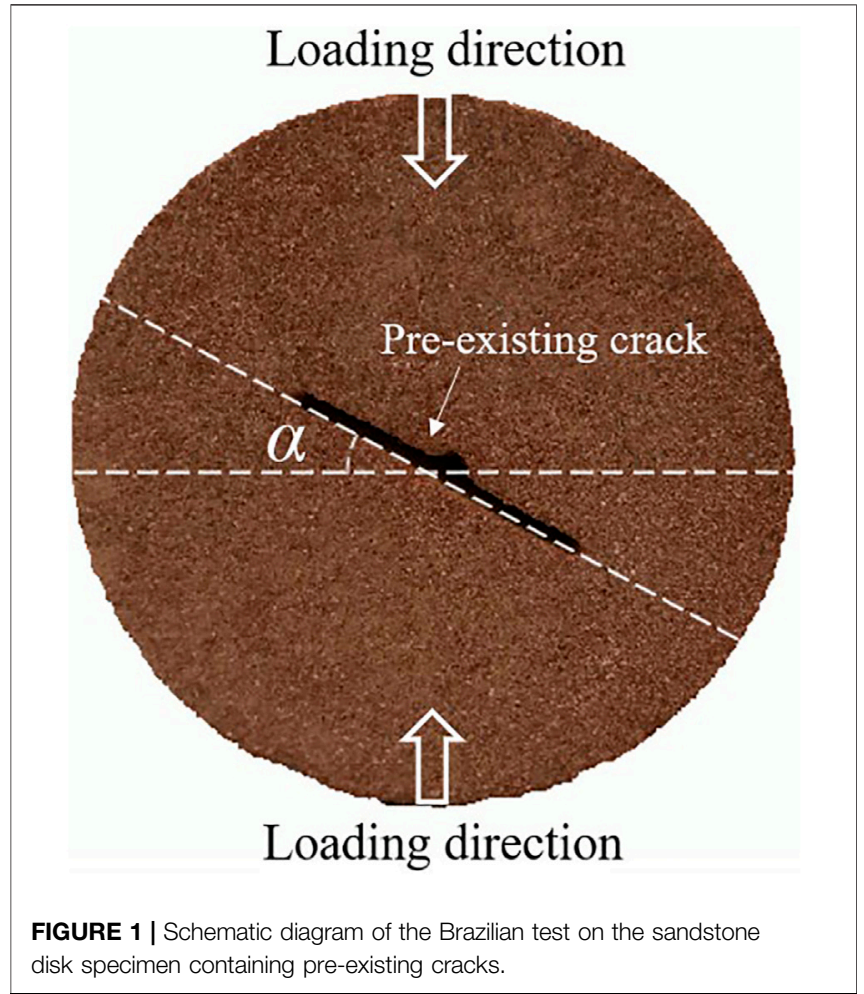

which are $20 \mathrm{~mm}$ in length and $0.8 \mathrm{~mm}$ in width. Before testing, the specimens were dried for $36 \mathrm{~h}$ at $60^{\circ} \mathrm{C}$.

The Brazilian test on the sandstone specimen with preexisting cracks was conducted in the electronic universal testing machine CMT5504, whose capacity is $50 \mathrm{kN}$. In this test, the displacement control mode is employed to apply the axial force at a rate of $0.1 \mathrm{~mm} / \mathrm{min}$, which can ensure that the sandstone specimen is under a quasi-static loading condition. A high-speed video camera was employed to capture the extension of new cracks in the specimen. As shown in Figure 1, the crack inclination $(\alpha)$ is defined as the preexisting crack angle with respect to the horizontal direction, and the loading direction is vertical.

The Brazilian tensile strength is calculated by the following equation:

$$
\sigma_{t}=\frac{2 P_{\max }}{\pi D L}
$$

where $P_{\max }$ is the peak loading force applied to the sandstone specimen and $D$ and $L$ are the diameter and thickness of the specimen, respectively. In Tavallali's research studies $[9,10]$, the applicability of Eq. 1 has been illustrated.

\section{RESULTS AND DISCUSSIONS}

The loading force-displacement curves of sandstone specimens are presented in Figure 2A. In the initial stage,

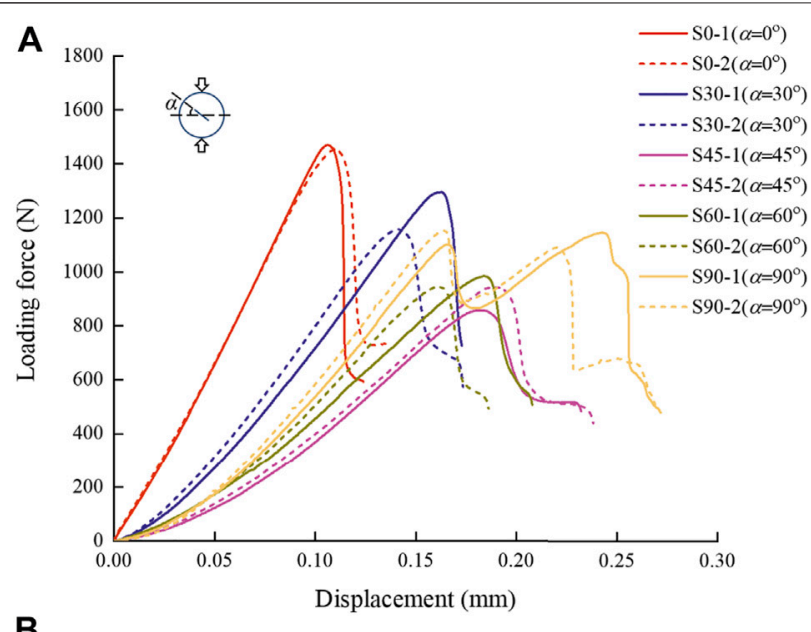

B

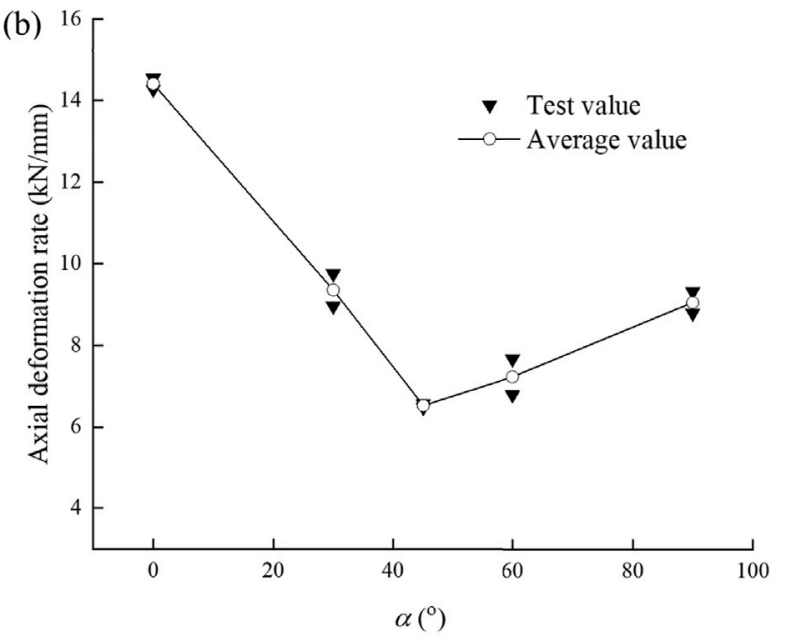

C

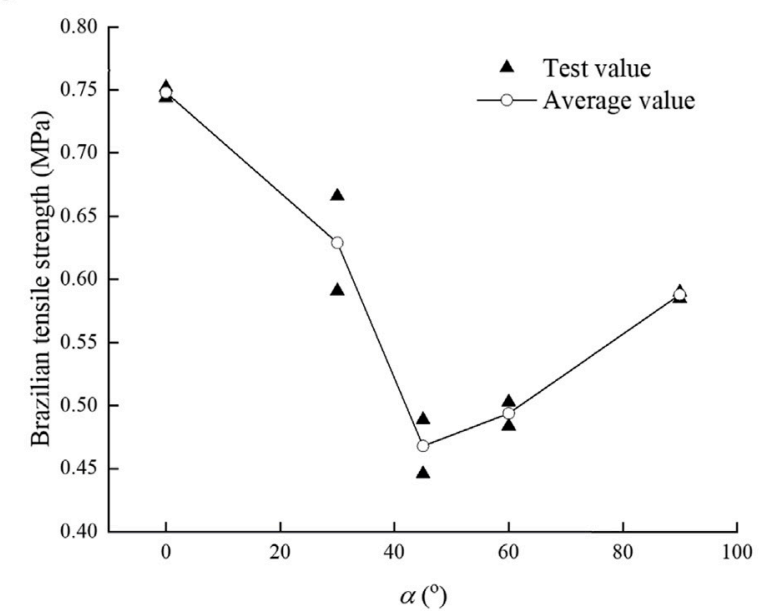

FIGURE 2 | (A) Loading force-displacement curves of sandstone specimens; (B) relationship between the axial deformation rate and the crack inclination; (C) relationship between the tension strength and the crack inclination. 
TABLE 1 | Brazilian test results of the sandstone specimen.

\begin{tabular}{|c|c|c|c|c|c|c|c|}
\hline \multirow[t]{2}{*}{ Serial number } & \multirow[t]{2}{*}{ Crack inclination } & \multirow[t]{2}{*}{ Diameter (mm) } & \multirow[t]{2}{*}{ Thickness (mm) } & \multicolumn{2}{|c|}{ Peak loading force } & \multicolumn{2}{|c|}{ Brazilian tensile strength } \\
\hline & & & & $\begin{array}{c}\text { Test value } \\
\text { (kN) }\end{array}$ & $\begin{array}{l}\text { Average value } \\
(\mathbf{k N})\end{array}$ & $\begin{array}{c}\text { Test value } \\
\text { (MPa) }\end{array}$ & $\begin{array}{c}\text { Average value } \\
\text { (MPa) }\end{array}$ \\
\hline So-1 & $0^{\circ}$ & 49.79 & 25.04 & 1.471 & 1.463 & 0.752 & 0.748 \\
\hline so-2 & $0^{\circ}$ & 49.85 & 24.98 & 1.455 & & 0.744 & \\
\hline S30-1 & $30^{\circ}$ & 49.96 & 24.82 & 1.296 & 1.227 & 0.666 & 0.629 \\
\hline S30-2 & $30^{\circ}$ & 49.86 & 25.02 & 1.158 & & 0.591 & \\
\hline S45-1 & $45^{\circ}$ & 49.87 & 24.56 & 0.858 & 0.901 & 0.446 & 0.468 \\
\hline S45-2 & $45^{\circ}$ & 49.79 & 24.68 & 0.943 & & 0.489 & \\
\hline S60-1 & $60^{\circ}$ & 49.93 & 24.97 & 0.985 & 0.966 & 0.503 & 0.494 \\
\hline S60-2 & $60^{\circ}$ & 49.83 & 24.97 & 0.946 & & 0.484 & \\
\hline S90-1 & $90^{\circ}$ & 49.87 & 25.03 & 1.146 & 1.150 & 0.585 & 0.588 \\
\hline S90-2 & $90^{\circ}$ & 49.86 & 24.98 & 1.153 & & 0.590 & \\
\hline
\end{tabular}

we can see that the deformation of specimen increases quickly, which is caused by the compaction of pores in the specimen. After compaction, the loading force rises linearly before the plastic-hardening stage. When the specimen is close to failure, the curve obviously flattens out, and the propagation of preexisting cracks captured by a high-speed camera is at this stage. Exceptionally, the loading force rises linearly in the initial stage when $\alpha=0^{\circ}$, and two peaks appear on the loading force-displacement curves when $\alpha=90^{\circ}$. For the first peak, the new transfixion crack extending from the pre-existing crack appeared, and the specimen is destructed into two parts, but the two parts of the specimen are still intact and have a certain bearing capacity. When the load continues to increase, the two pieces of the specimen are broken, and the second peak appears on the curve.

The slope at the linear elastic stage of the curves shown in Figure 2 can characterize the axial deformability with respect to the axial loading force of the sandstone specimen. Figure 2B shows the relationship between the axial deformation rate and the crack inclination. We can see that the axial deformability variation displayed a "V" shape with respect to the crack inclination. The strongest axial deformation resistance is at $\alpha$ $=0^{\circ}$, while the weakest is at $\alpha=45^{\circ}$. Due to the existence of crack inclination (not $0^{\circ}$ or $90^{\circ}$ ), there are dislocation deformations on both sides of the pre-existing crack, which increase the axial deformability of the specimen. The inclination of the pre-existing crack also has an influence on the failure strength of the specimen. The tested Brazilian tensile strength (BTS) values are listed in Table 1, and the BTS variation with pre-existing crack inclination is plotted in Figure 2C. The BTS variation also displayed a "V" shape with respect to the crack inclination. The maximum failure strength appears at $0^{\circ}$, and the minimum is at $45^{\circ}$. The sandstone disk specimen shows obvious anisotropic characteristics in strength and deformation, which are caused by the existence of pre-existing cracks.

The propagation evolution of new cracks before failure is observed by the high-speed camera with 250 FPS (frames per second). The resolution of the image taken by the high-speed camera is $1,624 \times 1,224$ pixels. The failure pattern of the specimen is shown in Figure 3A. The inclination of preexisting cracks also affects the initiation and propagation of new cracks under loading. There is no obvious dislocation phenomenon on both sides of the new crack. For the point of new crack initiation, except for the specimen at $0^{\circ}$, the initiation points in which are near the center of the preexisting crack. The initial new cracks of the other specimens are generated near the tip of the pre-existing crack. In terms of extension direction, the new crack does not continue to extend along the direction of the pre-existing crack. The propagation path of new cracks is significantly affected by the direction of the load. The wing crack forms at the tip of the pre-existing crack, propagates along the direction perpendicular to the maximal principal stress, and eventually extends to the loading end. The new crack in specimens at $0^{\circ}$ and $90^{\circ}$ is linear, and that in other specimens is " $Z$ "-shaped (Figure 3A).

In addition, some small cracks near the loading end appear in specimens at $30^{\circ}, 45^{\circ}$, and $60^{\circ}$. These small cracks do not connect with the cracks extending from pre-existing cracks, and appear later, which would be caused by the load reaching the failure strength of sandstone itself. From the perspective of the final failure mode, the new cracks have a certain symmetry with respect to the specimen center, while in the Brazilian test, the stress distribution in the specimen has a symmetry with respect to the specimen center, which indicates that the extension direction of pre-existing cracks is controlled by the stress state in the specimen.

Additionally, as shown in Figures $\mathbf{3 A}, \mathbf{B}$, tensile microcracks in the $0^{\circ}$ specimen can be observed at $\times 5,000$ magnification. Different from microcracks caused by shear failure [11], the surfaces of the microcrack are relatively smooth and clean. Moreover, the crack trajectory shows that the microcrack is transgranular. A small amount of hair-line tensile cracks can be observed in the vicinity of tensile microcracks (in the yellow box). However, the shear microcracks in the $75^{\circ}$ specimen indicated that the surfaces of shear microcracks are rough and rugged, and there are obvious signs of sliding friction on both sides of the microcracks, such as exfoliated debris (Figure 3C). A lot of flocculent microcracks are concentrated in the en-echelon microcracking zone (in the red box), which is adjacent to the shear microcrack. 

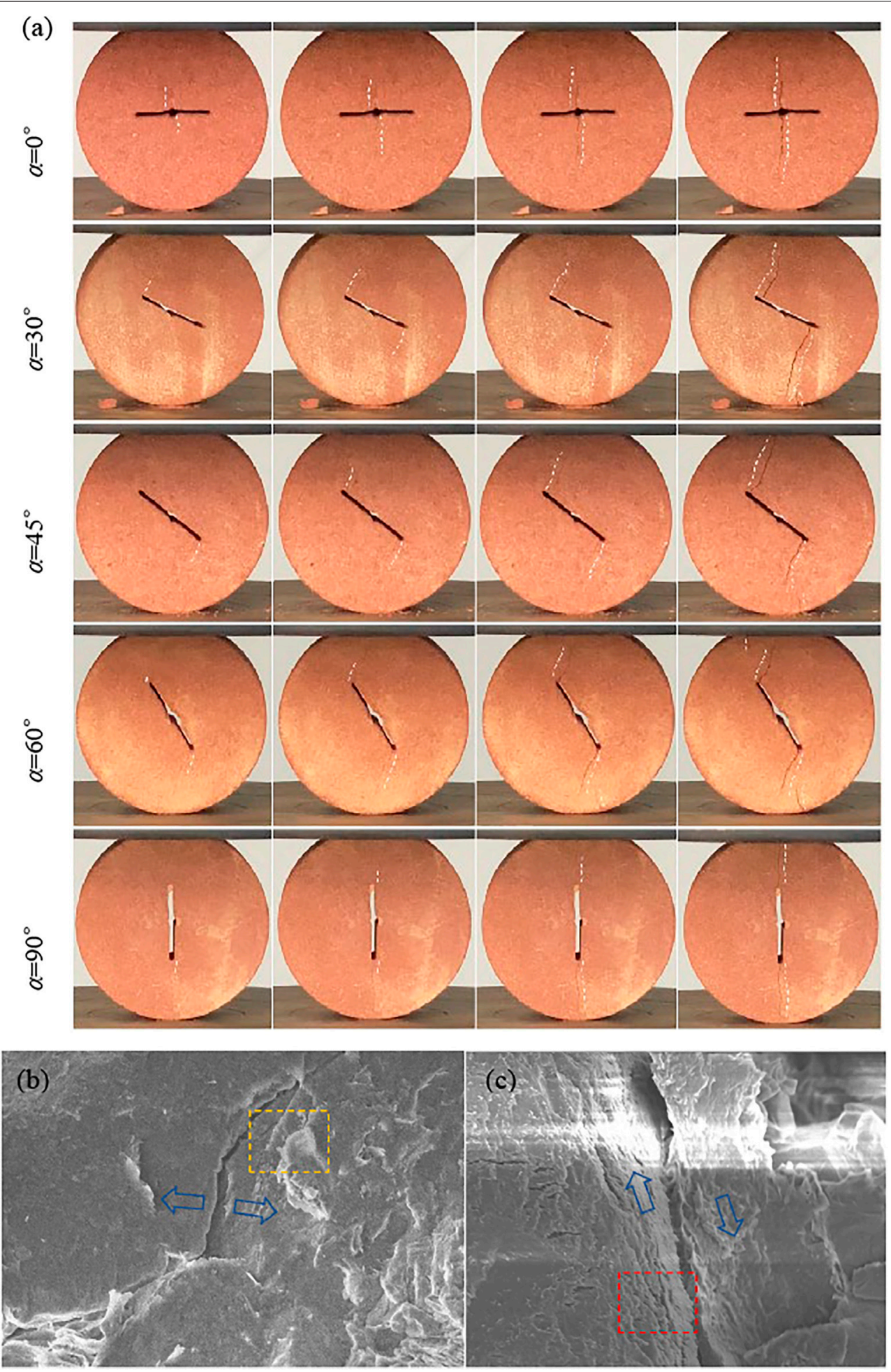

FIGURE 3 | (A) Failure pattern of the specimen captured by a high-speed camera; (B) tensile microcrack in the $0^{\circ}$ specimen; (C) shear microcrack in the $75^{\circ}$ specimen.

\section{CONCLUSION}

Both the axial deformability and the BTS variation displayed a "V" shape with respect to the crack inclination. The strongest axial deformation resistance is at $\alpha=0^{\circ}$, while the weakest is at $\alpha=45^{\circ}$. The existence of pre-existing cracks results in the anisotropy of sandstone in strength and deformation under tension condition, and the strength and failure behavior of rock depend on the crack 
inclination. The forces along both sides of the pre-existing crack are the reason for the drop of the strength and deformation resistance of sandstone, resulting in the tension crack at the tip of the pre-existing crack. In the future work, the mechanical properties of rock containing multiple pre-existing flaws under tensile conditions will be discussed.

\section{DATA AVAILABILITY STATEMENT}

The raw data supporting the conclusions of this article will be made available by the authors, without undue reservation.

\section{AUTHOR CONTRIBUTIONS}

JY was responsible for defining the research aims, collating and reviewing the literature and previous research for the

\section{REFERENCES}

1. Chen L-H, Chen W-C, Chen Y-C, Benyamin L, Li A-J. Investigation of Hydraulic Fracture Propagation Using a post-peak Control System Coupled with Acoustic Emission. Rock Mech Rock Eng (2015) 48(3): 1233-48. doi:10.1007/s00603-014-0620-y

2. Zhou XP, Xia EM, Yang HQ, Qian QH. Different Crack Sizes Analyzed for Surrounding Rock Mass Around Underground Caverns in Jinping I Hydropower Station. Theor Appl fracture Mech (2012) 57(1):19-30. doi:10.1016/j.tafmec.2011.12.004

3. Kilburn CR, Petley DN. Forecasting Giant, Catastrophic Slope Collapse: Lessons from Vajont, Northern Italy. Geomorphology (2003) 54(1-2):21-32. doi:10.1016/s0169-555x(03)00052-7

4. Bobet A, Einstein HH. Fracture Coalescence in Rock-type Materials under Uniaxial and Biaxial Compression. Int J Rock Mech Mining Sci (1998) 35(7): 863-88. doi:10.1016/s0148-9062(98)00005-9

5. Li Y-P, Chen L-Z, Wang Y-H. Experimental Research on Pre-cracked marble under Compression. Int J Sol Structures (2005) 42(9-10):2505-16. doi:10.1016/ j.ijsolstr.2004.09.033

6. Sagong M, Bobet A. Coalescence of Multiple Flaws in a Rock-Model Material in Uniaxial Compression. Int J Rock Mech Mining Sci (2002) 39(2):229-41. doi:10.1016/s1365-1609(02)00027-8

7. Wong R, Law C, Chau KT, Shen W. Crack Propagation from 3-D Surface Fractures in PMMA and marble Specimens under Uniaxial Compression. Int J Rock Mech Mining Sci (2004) 41(Suppl. 1):1. doi:10.1016/ j.ijrmms.2004.03.016

8. Yang S-Q, Liu X-R, Jing H-W. Experimental Investigation on Fracture Coalescence Behavior of Red sandstone Containing Two Unparallel discussion, conceptualizing the article structure, writing the manuscript draft, and figure conception and execution. $\mathrm{XC}, \mathrm{HZ}$ and JY jointly agreed upon the research objectives; provided supportive analyses and interpretations; and contributed, reviewed, and edited text. YQ contributed and edited text.

\section{FUNDING}

This work was financially supported by the National Natural Science Foundation of China (Grant No. 11802145), the Natural Sciences Fund for Colleges and Universities in Jiangsu Province (Grant No. 20KJB560036), and the Nantong Science and Technology Plan Project (Grant No. JC2020122). Jiangsu Province College Student's innovation and entrepreneurship training program (202110304159H).

Fissures under Uniaxial Compression. Int J Rock Mech Mining Sci (2013) 63(63):82-92. doi:10.1016/j.ijrmms.2013.06.008

9. Tavallali A, Vervoort A, Sciences M. Effect of Layer Orientation on the Failure of Layered sandstone under Brazilian Test Conditions. Int J Rock Mech Mining Sci (2010) 47(2):313-22. doi:10.1016/j.ijrmms.2010.01.001

10. Tavallali A, Vervoort AJJORM, Engineering G (2013). "Behaviour of Layered sandstone under Brazilian Test conditions:Layer Orientation and Shape Effects." J. Mech. Geotech. Eng. 5(005), 366-77. doi:10.1016/j.jrmge.2013.01.004

11. Jia $\mathrm{C}, \mathrm{Xu}$ W, Wang H, Zhang QJBOEG, Environment T. Experimental Investigation of the Mechanical and Permeability Characteristics of Volcanic Breccia. Bull Eng Geology Environ (2020) 80(1):1-12. doi:10.1007/s10064-020-01949-X

Conflict of Interest: The authors declare that the research was conducted in the absence of any commercial or financial relationships that could be construed as a potential conflict of interest.

Publisher's Note: All claims expressed in this article are solely those of the authors and do not necessarily represent those of their affiliated organizations, or those of the publisher, the editors, and the reviewers. Any product that may be evaluated in this article, or claim that may be made by its manufacturer, is not guaranteed or endorsed by the publisher.

Copyright (c) 2021 Cao, Zhang, Yu, Yu and Qing. This is an open-access article distributed under the terms of the Creative Commons Attribution License (CC BY). The use, distribution or reproduction in other forums is permitted, provided the original author(s) and the copyright owner(s) are credited and that the original publication in this journal is cited, in accordance with accepted academic practice. No use, distribution or reproduction is permitted which does not comply with these terms. 